\title{
Haaga-Helia
}

ammattikorkeakoulu

HUOM! Tämä on alkuperäisen artikkelin rinnakkaistallenne. Rinnakkaistallenne saattaa erota alkuperäisestä sivutukseltaan ja painoasultaan.

Käytä viittauksessa alkuperäistä lähdettä:

Dirin, M., Dirin, A. \& Laine, T. (2015). User-Centered Design of a Context-Aware Nurse Assistant (CANA) at Finnish elderly Houses. IMCOM15. Proceedings of the 9th International Conference on Ubiquitous Information Management and Communication Bali, Indonesia - January 08 - 10, 2015. New York, ACM.

PLEASE NOTE! This in an electronic self-archived version of the original article. This reprint may differ from the original in pagination and typographic detail.

Please cite the original version:

Dirin, M., Dirin, A. \& Laine, T. (2015). User-Centered Design of a Context-Aware Nurse Assistant (CANA) at Finnish elderly Houses. IMCOM15. Proceedings of the 9th International Conference on Ubiquitous Information Management and Communication Bali, Indonesia - January 08 - 10, 2015. New York, ACM.

The final authenticated publication is available at: $\underline{\mathrm{https}}$ ://dl.acm.org/citation.cfm?id=2701225

Copyright @ 2015 by the Association for Computing Machinery, Inc. 


\section{User-Centered Design of a Context-Aware Nurse Assistant (CANA) at Finnish Elderly Houses}

\author{
Mitra Dirin \\ Department of Health Care, \\ Metropolia University of Applied \\ Sciences, Helsinki, Finland \\ $+358404126406$ \\ mitra.dirin@gmail.com
}

\author{
Amir Dirin \\ Department of Business Information \\ Technology, Haaga-Helia University of \\ Applied Sciences, Helsinki, Finland \\ $+358504869666$ \\ amir.dirin@haaga-helia.fi
}

\author{
Teemu H. Laine \\ Department of Information and \\ Computer Engineering, Ajou \\ University, Korea \\ $+82312193549$ \\ teemu@ubilife.net
}

\begin{abstract}
In this age of mobile and ubiquitous computing, many nurses working in the healthcare sector still utilize traditional tools (e.g., paper calendars and clipboards) and pre-installed mobile applications (e.g., web browser, calendar) in their work activities. There exists a variety of mHealth applications, but none of them combines essential professional tools for nursing. We tackled this problem in the Finnish elderly house context through the User Centered Design (UCD) method whereby the target users actively participate in the design process. Together with 12 nurses, we first identified their profiles and their expectations on work-related mHealth application functionalities. The results were utilized in conceptual design of Context-Aware Nurse Assistant (CANA), which combines the identified functionalities and provides contextsensitive services to consolidate nurses' work activities. This paper contributes to the field of ubiquitous healthcare as follows: 1) initial user survey that shows the need for the proposed CANA system; 2) UCD design process of CANA and its suitability for designing ubiquitous healthcare systems, 3) technical architecture based on modular web services and 4) evaluation results of a low-fidelity CANA prototype. These results are of interest to software designers, healthcare professionals and context-aware application developers.
\end{abstract}

\section{Categories and Subject Descriptors}

[Human-Centered Computing]: Ubiquitous and mobile computing - Ubiquitous and mobile computing systems and tools. [HumanCentered Computing]: Interaction design - Interaction design process and methods - User centered design. [Applied Computing]: Life and medical sciences - Health care information systems.

\section{General Terms}

Design, Experimentation, Human Factors

\section{Keywords}

User centered design, context-aware mobile application, mHealth, nursing.

\section{INTRODUCTION}

Smartphones are popular gadgets which people are carrying in their everyday lives. They are often used in various contexts through preinstalled applications such as calendar or email which are similar across mobile platforms. Third party applications, however, are applications which users download from application stores into the devices. As the smartphone has gained popularity, third party application developers have started creating applications to assist people in their work-related activities. These productivity applications are being used to enhance and consolidate the existing tools (e.g., clipboards, paper calendars, books) that people have previously used in their work. For example, smartphones and less smart mobile devices have been utilized in business [1], [2] and education [3]-[6] sectors for several years. However, the potential of smartphones has not been fully utilized in some sectors such as healthcare. In particular, nurses at hospitals and elderly houses have so far lagged behind the trend of smartphone adoption for consolidating professional tasks despite of the fact that smartphones and other mobile technology has been applied in nursing education [4], [6], [7].

Electronic health, or $e$ Health, is a field at the intersection of medical informatics, public health and business where there Internet and related technologies facilitate health service provision [8]. Mobile health, or $m$ Health, is an emerging subset of eHealth where services related to healthcare are accessed via mobile devices. Due to ubiquity of sensor-equipped smartphones, mHealth applications can also support context-awareness, thus providing appropriate services for a given situation. A typical context-aware mHealth service is a patient monitoring system which combines body sensors, mobile devices and wireless communication technologies to enable remote monitoring of patients [9]-[11]. To our knowledge, until today context-aware mHealth services have not been developed to meet the professional needs of nurses in Finland.

The Ministry of Social Affairs and Health in Finland promotes new service development in their national wide policy for elderly people [12]. This includes improving the quality of services and reducing costs with higher productivity [13]. Additionally, the nationwide governmental policy has conducted many initiatives to enhanced technology in the health sectors such as electronic prescriptions [14]. Moreover, initiatives have been made to improve existing applications, such as a patient-centered guide that encourages patients to use eHealth services, and eHealth services for families with children under school age [15], [16].

Based on our initial user study, nurses are often busy at work and do not have time to search for a particular application or service in their smartphones at the time of need. As result, mHealth applications and services are required to be adaptive and perform appropriately based on the context of use. In addition to saving time through adaptive operation, employing context-awareness in mHealth applications has other motivations. Firstly, nurses by law are not allowed to use their mobile devices in all premises at hospitals. Secondly, the concept of mHealth is more efficient if the services are invoked automatically when they are needed.

The security and ethics related to patients' information in the healthcare sector have always been a major concern. Utilization of internet and mobile technologies increases information integrity risks such as exposing sensitive information. Rezende et al. [17] 
have studied what codes of ethics are considered in the development and implementation of eHealth services and how they are enforced. Additionally, developing an application especially for smart devices requires extensive considerations due technical constraints such as small screen size, limited input/output mechanisms, and limited resources (battery, memory, CPU). Finally, an essential requirement for context-aware application design is to understand the target users' contexts in order to provide contextualized services. Aforementioned constraints require that the target users should be directly involved in the application development. Thus, in this study we employ the User Centered Design (UCD) methodology [18] to ensure the users' involvement in all stages of development.

In this paper we propose a novel mHealth system titled ContextAware Nurse Assistant (CANA). Novelty of this application stems from the UCD process which is deep-rooted in the target users' needs elicited by a qualitative survey. The proposed CANA application focuses on nurses at elderly houses in Espoo, Finland. The aim is to consolidate nurses' daily work activities through context-aware services in a single smartphone application.

\section{BACKGROUND}

There have been initiatives to introduce Internet and mobile technologies in healthcare, such as web-based and mobile-based interventions [8]. However, these tools do not support an individual employee's needs. Mobile devices are increasingly important instruments in the toolkit of public health professionals and researchers [8]. Eysenbach [8] defines eHealth as an emerging field at the intersection of medical informatics, public health and business, referring to health services and information delivered or enhanced through the Internet and related technologies. In a broader sense, the term characterizes not only a technical development, but also a state-of-mind, a way of thinking, an attitude, and a commitment for networked, global thinking, to improve healthcare locally, regionally, and worldwide by using information and communication technology [8].

The World Health Organization report [19] indicates that there are various global initiatives to employ mobile devices in healthcare, such as health call centers, appointment reminders, mobile telemedicine and patient monitoring. Mobile health, or mHealth, is a subset of eHealth, which brings services related to healthcare (e.g., patient status monitoring) into mobile devices. In 2011, there were more than 17,000 mHealth related applications [20]. This number has increased ever since, thus easing the workflow of healthcare involving the patients, nurses and doctors.

Havelka analyzed mobile applications, mobile websites, e-book stores and databases that are commonly utilized in nursing work, suggesting that mobile applications for nursing and healthcare in general are on the rise [21]. As result, these mobile applications and resources extend the functions of a traditional library as a source of professional information. Wyatt and Krauskopf [22] also explored the use of smartphones in enhancing nursing practice by reviewing smartphone platforms, current practices, and available applications. They concluded that smartphones' portability, quick access to resources and a variety of healthcare applications makes these devices convenient to use in healthcare. Furthermore, a supportive environment with technical assistance is required for smartphone adoption. In another study, Putzer and Park investigated the factors which influence smartphone adoption among nurses $(\mathrm{N}=80)$. Their results suggest that smartphone adoption is influenced by observability, compatibility, job relevance, internal environment, and external environment. Some of these factors are administrative and therefore will require adjustment of policies and organizational practices at a high level. Some, such as job relevance and compatibility, can be largely influenced by choosing an application design method that takes into account the target users' needs. To achieve this, we employ the User Centered Design method (UCD) [18] which is described in the next section.

Previous surveys have shown that there exist several categories of smartphone applications related to nursing work [7], [21], [22]. Examples of these categories are drug reference systems (e.g., ePocrates), medical calculators (e.g., MedCalc), medical research databases (e.g., Skyscape OCM), professional communities (e.g., QuantiaMD), and applications for specific fields such as radiology (e.g., Lieberman's iRadiology Classics) and pediatrics (e.g., 5 Minute Clinical Consult). Based on our understanding, these applications are not context-aware, i.e. they only focus on tasks occurring on the screen, such as information retrieval and calculations. Consequently, these applications cannot adapt to the user's needs in a given working context.

Since the concept of ubiquitous computing was coined in the 1990s, researchers have developed context-aware systems that adapt their behavior based on context information such as the user's location, time of the day, the user's current activity, the user's emotional state, focus of attention, and so forth [23]-[25]. In the healthcare sector, context-aware mHealth applications have been applied particularly in patient monitoring through body sensor networks [9]-[11]. There have also been research efforts to create contextaware applications that focus on facilitating nurses' work. Nelwan et al. [26] described a system that allows a nurse to monitor a patient's physiological signals using a PDA device, which can also receive alarms at specific events. Bardram [27] implemented a context-aware hospital bed and a pill container. The bed is aware of the patient's identity, their condition and treatment, and nearby items or persons. The pill container can identify the patient by fingerprint and can communicate with a patient's display on the bed, thus helping a nurse to choose the correct drug. In last example, a context-aware healthcare system was evaluated in a real-world deployment [28]. The system aims at alleviating coordination and collaboration challenges of clinical workers (i.e. doctors and nurses) through location tracking, context-aware scheduling on interactive displays, and social awareness through mobile devices. After four months of deployment, the system was still in use and a user study revealed that the provision of context information regarding colleagues and operating rooms was found to be particularly useful.

Aforementioned mobile and context-aware applications focus on limited aspects of the nurses' work. To this date there exist no systems that unify the features that are essential to nurses' work and provide context-aware access to those features.

\section{DESIGN METHODOLOGY}

The term User Centered Design (UCD) was originated by Don Norman during 1980s [18]. UCD and development of interactive systems and devices have an increasing importance in product development in organizations [18]. To create a usable system, we need to involve users continuously, and based on the users' feedback, modify the design [29], [30]. UCD cuts costs [14] and improves usability, since it continually focuses on the essential needs of the user from an early stage of the development, hence ensuring appropriate functionalities [31]. The ISO standard "Human-centred design for interactive systems" [32] defines three different design solutions for UCD as: I. Cooperative design; 
designers and users are involved in all stages II. Participatory design; users occasionally participate in the design process, III. Contextual design; design is based on the actual context. In this paper we apply the participatory design approach.

The application concept development in this study is based on a UCD framework for addressing usability and user experience in mobile learning application development [31]. Figure 1 presents the UCD framework processes for creating CANA.

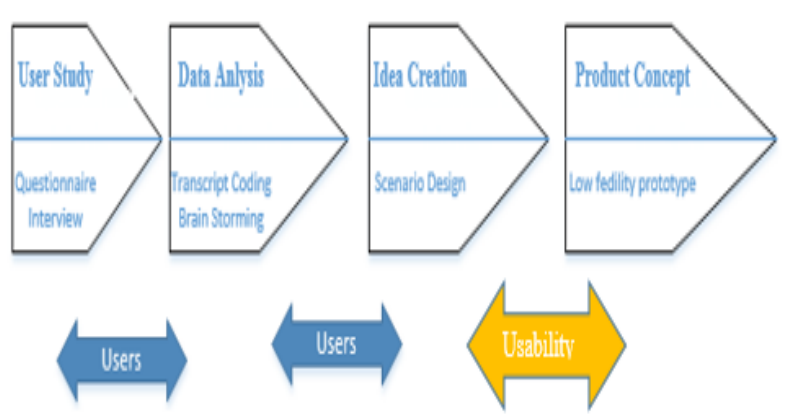

Figure 1. UCD process of the CANA system

The framework requires users' involvement in all stages of the application concept development. Accordingly, concept design consists of the following phases:

- User Study - In this phase the designer aims to learn the users' current ways and tools to handle their work related tasks by applying methods such as questionnaire and semi-structured interviews.

- Data Analysis- Analyze further the collected data in the first phase. This analysis consists of an analysis of transcript coding of user interviews [33] as well as user task and environment analysis [37]. The overall requirements of the target application are identified in this phase.

- Idea Creation - By applying methods such as affinity diagrams [34], actions and requirements prepared at the previous phases are categorized. Use-case scenarios are also applied as a design method to propose the application concept to the target users.

- $\quad$ Product Concept - Prepared scenarios are shared with 3-5 users who provide feedback. A scenario reflects a potential application concept. The users' feedback on the scenarios are analyzed in order to validate the concept's feasibility and also to ensure that the users and designers have the same understanding about the application. If necessary, designers may return back to the previous phase to modify the scenarios.

After validating the concept, a prototype is designed based on the scenarios, followed by a usability evaluation on the prototype with target users.

We conducted an initial user study based on the aforementioned framework to understand the target users, and a subsequent analysis to identify their professional needs. The framework, which is based on the UCD principles, suggests that the users of the target application should be involved in all stages of the application development. Consequently, qualitative research was conducted among nurses and doctors at two elderly houses in Espoo. Resulting user profiles, scenarios and an application prototype are presented in the following sections.

\section{USER STUDY}

In order to design a mHealth application prototype with UCD method, we first must understand who the potential target users are and what are their needs regarding the application. For this reason we performed an initial user study with potential users.

\subsection{Data Collection}

The initial user study was conducted with 12 nurses and a doctor at two elderly houses in Espoo, Finland. These users were chosen among doctors, specialist nurses, registered nurses, practical nurses and registered nurse students with practical nursing education background. Semi-structured interview was selected as a method for eliciting in-depth information about the users' requirements regarding the application. Face-to-face interviews were conducted during two weeks in spring 2014 at Aurorankoti and Kuusikoti elderly houses in Espoo, Finland, as well as at the Metropolia University of Applied Sciences. The interview sessions were recorded with a mobile phone for transcribing and analysis. At the beginning of interview sessions, the participants were briefed about the interview's goals. Additionally, the participants were asked to sign a consent form for recoding the session and contacting them later should further questions arise. The interviews took place after the participants' working hours and one session lasted approximately 30 minutes.

Table 1 shows profiles of the users and how they currently use mobile devices. There were 12 users in total of whom two were male and the rest were female. The age distribution varied from 21 years up to 61 years old (average: 36 ). Majority of the users were Finnish nationals. Two of the users had foreign nationalities, but they were able to speak Finnish fluently. $90 \%$ of the users had smartphones and $83 \%$ of them considered themselves to be expert users. Additionally, these expert users had experience with communication applications such as Viber, WhatsApp and Facebook. Conversely, novice users did not have much experience with smartphones and did not often download applications nor use the browser.

Table 1. User profiles

\begin{tabular}{|l|l|l|l|l|l|}
\hline $\begin{array}{c}\text { Ag } \\
\mathbf{e}\end{array}$ & $\begin{array}{c}\text { M/ } \\
\text { F }\end{array}$ & Occupation & $\begin{array}{c}\text { Wor } \\
\mathbf{k} \\
\mathbf{e x p}\end{array}$ & $\begin{array}{c}\text { Smart } \\
\text { phone } \\
\text { user }\end{array}$ & \multicolumn{1}{|c|}{$\begin{array}{c}\text { Most used } \\
\text { applications }\end{array}$} \\
\hline 29 & $\mathrm{~F}$ & Physician & $4 \mathrm{Y}$ & Expert & Call and e-mail \\
\hline 58 & $\mathrm{~F}$ & $\begin{array}{l}\text { Practical } \\
\text { nurse }\end{array}$ & $6 \mathrm{Y}$ & Novice & Call and SMS \\
\hline 61 & $\mathrm{~F}$ & $\begin{array}{l}\text { Registered } \\
\text { nurse }\end{array}$ & $9 \mathrm{Y}$ & Expert & $\begin{array}{l}\text { Facebook and } \\
\text { email }\end{array}$ \\
\hline 26 & $\mathrm{~F}$ & $\begin{array}{l}\text { Registered } \\
\text { nurse } \\
\text { and }\end{array}$ & $5 \mathrm{Y}$ & Expert & $\begin{array}{l}\text { Facebook, } \\
\text { mail } \\
\text { WhatsApp }\end{array}$ \\
\hline 21 & $\mathrm{~F}$ & $\begin{array}{l}\text { Practical } \\
\text { nurse } \\
\text { (registered } \\
\text { nurse } \\
\text { student }\end{array}$ & $1.5 \mathrm{Y}$ & Expert & Clock, Google \\
\hline 23 & F & $\begin{array}{l}\text { Practical } \\
\text { nurse }\end{array}$ & $3 \mathrm{Y}$ & Expert \\
nurse & $\begin{array}{l}\text { News, calls and } \\
\text { SMS }\end{array}$ \\
\hline
\end{tabular}




\begin{tabular}{|l|l|l|l|l|l|}
\hline 26 & M & $\begin{array}{l}\text { Practical } \\
\text { nurse } \\
\text { (registered } \\
\text { nurse } \\
\text { student) }\end{array}$ & $9 \mathrm{Y}$ & Expert & $\begin{array}{l}\text { Facebook, } \\
\text { email, calendar }\end{array}$ \\
\hline 47 & F & $\begin{array}{l}\text { Registered } \\
\text { nurse }\end{array}$ & $3 \mathrm{Y}$ & Novice & Call and SMS \\
\hline 49 & $\mathrm{~F}$ & $\begin{array}{l}\text { Specialist } \\
\text { nurse }\end{array}$ & $18 \mathrm{Y}$ & Expert & $\begin{array}{l}\text { Calendar, } \\
\text { notepad, email } \\
\text { and Facebook }\end{array}$ \\
\hline 28 & $\mathrm{~F}$ & $\begin{array}{l}\text { Practical } \\
\text { nurse }\end{array}$ & $6 \mathrm{Y}$ & Expert & $\begin{array}{l}\text { Calendar, } \\
\text { Facebook, email }\end{array}$ \\
\hline 30 & $\mathrm{~F}$ & $\begin{array}{l}\text { Practical } \\
\text { nurse }\end{array}$ & $5 \mathrm{Y}$ & Expert & $\begin{array}{l}\text { Facebook, } \\
\text { calendar }\end{array}$ \\
\hline
\end{tabular}

\subsection{Data Analysis}

In this phase, in order to understand the nurses' needs, the recorded data were categorized and analyzed by applying data analysis methods such as user and task analysis [35] and transcript coding [33]. These methods help identify the actions and activities from interview transcripts. The actions (e.g., performing a particular task) and the activities (e.g., action that is performed at a specific time) for each user were listed and categorized accordingly. Afterwards, a merged list of actions for all users was prepared. We applied affinity diagrams and brain storming to compose a list of potential application requirements based on commonly quoted actions.

Table 2 shows samples of tasks that the users reported to carry out often with mobile devices in different environments. Frequency indicates how often a task is carried out in a working day.

Table 2. Samples of tasks, their frequencies and environments

\begin{tabular}{|l|l|l|}
\hline \multicolumn{1}{|c|}{ Task } & Freq. & \multicolumn{1}{c|}{ Environment } \\
\hline game & 9 & Spare time \\
\hline calendar & 8 & Work \\
\hline calendar & 8 & Spare time \\
\hline bank & 8 & Spare time \\
\hline email & 8 & Work \\
\hline browser & 11 & Work \& spare time \\
\hline education & 9 & Work \\
\hline education (Google) & 9 & Work \\
\hline medicine information search & 9 & Work \\
\hline Facebook & 10 & Spare time \\
\hline Facebook & 6 & Work \\
\hline chat / messenger & 10 & Social life \\
\hline messenger /group & 9 & Work \\
\hline trip planner & 8 & Work and social life \\
\hline notepad & 8 & Spare time \\
\hline
\end{tabular}

\begin{tabular}{|l|l|l|}
\hline notepad & 4 & Work \\
\hline clock & 12 & Work \& spare time \\
\hline maps & 11 & Work \& spare time \\
\hline navigator & 10 & Work \& spare time \\
\hline SMS & 12 & Work \& spare life \\
\hline phone calls & 12 & Work \& spare life \\
\hline Google translator & 3 & Work \\
\hline music & 1 & Work \\
\hline camera & 11 & Spare time \\
\hline
\end{tabular}

Figure 2 shows the most expected services, such as work shift table, notepad for measurements and work shift notifications, with frequencies. These services were identified by analyzing the interview transcripts. In other words, the nurses who participated in the study have high exceptions towards having these services in a mHealth application.

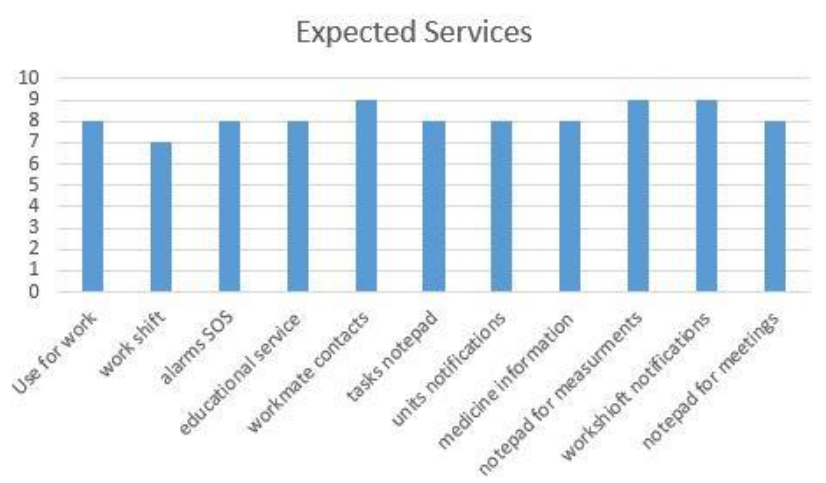

Figure 2. Most expected services

\section{PROTOTYPE DESIGN}

There are two aspects of the proposed CANA application which need to be tackled separately in the prototype design. First aspect is concept design based on the requirements that were elicited from the user study above. The second aspect is the technical application architecture which must be created in accordance to the user study, e.g., the application must adapt its behavior and a set of provided services based on the context of use.

\subsection{Concept development}

The requirements list which was prepared in the previous phase must to be transferred into an application concept. There are various concept design techniques such as scenario based design, which is particularly a suitable for mobile application concept design, as it speaks the users language and often avoids technical terms and complexities [36]. A scenario is a simple story which contains all the requirements that are identified earlier in a brain storming session in the data analysis phase. There can be more than one scenario to illustrate different aspects or users of the concept. User personas are embedded in these scenarios. Prepared scenarios are 
shared with target users for assessment. This is yet another opportunity for the target users to impact the concept design. An excerpt of a scenario devised for CANA is as follows:

Julia is a nurse. Her shift and working place often varies during a week. She noticed that today she has an evening shift at an elderly house in Espoo which is a new working place for her. She has received the elderly house details (address, phone number, etc.) through the city staff service. She is concerned about how to get there in time and also how to find the proper unit when she is there. Luckily, nowadays there is a new mobile application called CANA provided by a nurse agency in Helsinki...

We prepared three scenarios for nurses in total. The scenario above is a revised version of an original scenario, based on the users' feedback collected at a scenario review session. Based on revised scenarios, a low-fidelity prototype was designed which represents the look and feel of the application. CANA prototype contains user interface for all functionalities that are defined in the scenarios, such as work shift lists, medicine information search, emergency alarms, discussion board and department's booklet. Figure 3-5 illustrate the prototype's user interface mock-ups where the features were categorized under meaningful sections (Figure 3) according to the feedback received from nurses.

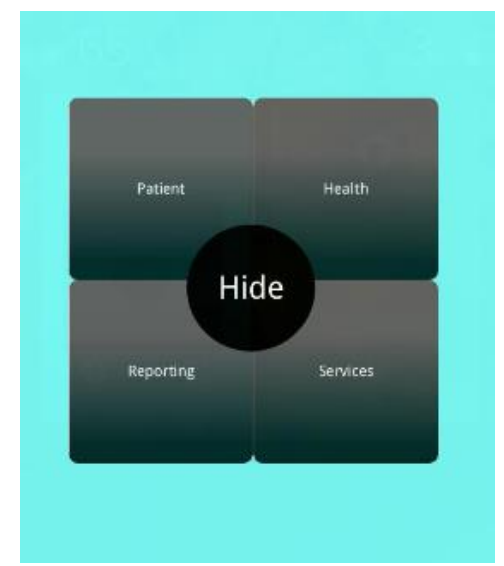

Figure 3. Category selection after login

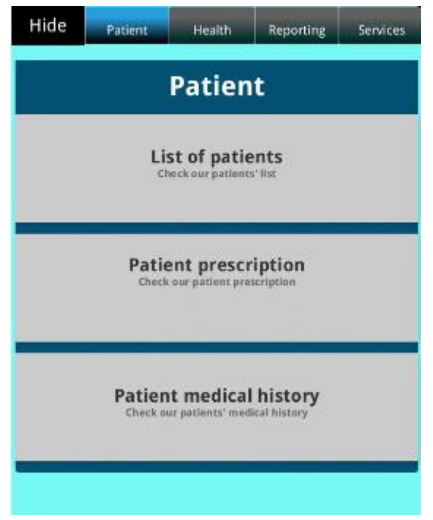

Figure 4. Patient tab

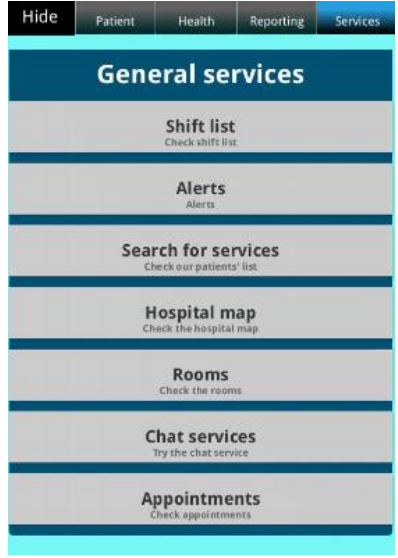

Figure 5. General services tab

\subsection{Architecture design}

After the conceptual design of CANA, we proceeded to design its technical architecture which is depicted in Figure 6. We chose to base the application on web services to maximize extensibility, accessibility and portability, thus being able to serve multiple client platforms. The CANA client makes RESTful HTTP requests to the server's Web Service Interface, and then presents the web service's response in appropriate format. As a consequence, the client is light-weight and most of its features require network connectivity. Conversely, the CANA server manages majority of the business logic and calculations.

The server has a modular structure which is divided into three groups: feature modules, support modules and context-awareness. Each Feature module manages a specific feature of the system, such as SOS alarms, schedule, and patient information. When the user activates one of these features, the client communicates with the respective module on the server through a web service interface. Feature modules may utilize support modules, context-awareness and data repositories in order to fulfill their tasks.

Support modules contain utilities and other common services that are shared by multiple feature modules. For example, the Users module handles user accounts and permissions, the Data Access module provides façades to the server database, and the Reporting module provides various reports and statistical data about the system. Clients can also directly access the interfaces of some of the support modules, such as Users module for registration, account management and login actions.

The core of context-sensitive service provision lies in the ContextAwareness module that maintains a context model for each user. In building the model, the context-awareness module utilizes raw context data received from the clients and other sources. For example, the context model keeps track of a nurse's current location, task, schedule and other information relevant to a nurse's work activities. The Context-Awareness module also contains a variety of inference algorithms that generate meaningful knowledge and events based on changes in the context. Indoor location is acquired by using an indoor positioning service [37]. Other modules, such as the SOS alarm module, can utilize the Context-Awareness module in order to provide contextually relevant services to the clients. The SOS alarm module could, for example, send alarms only to nurses who are currently working nearby the emergency location. 


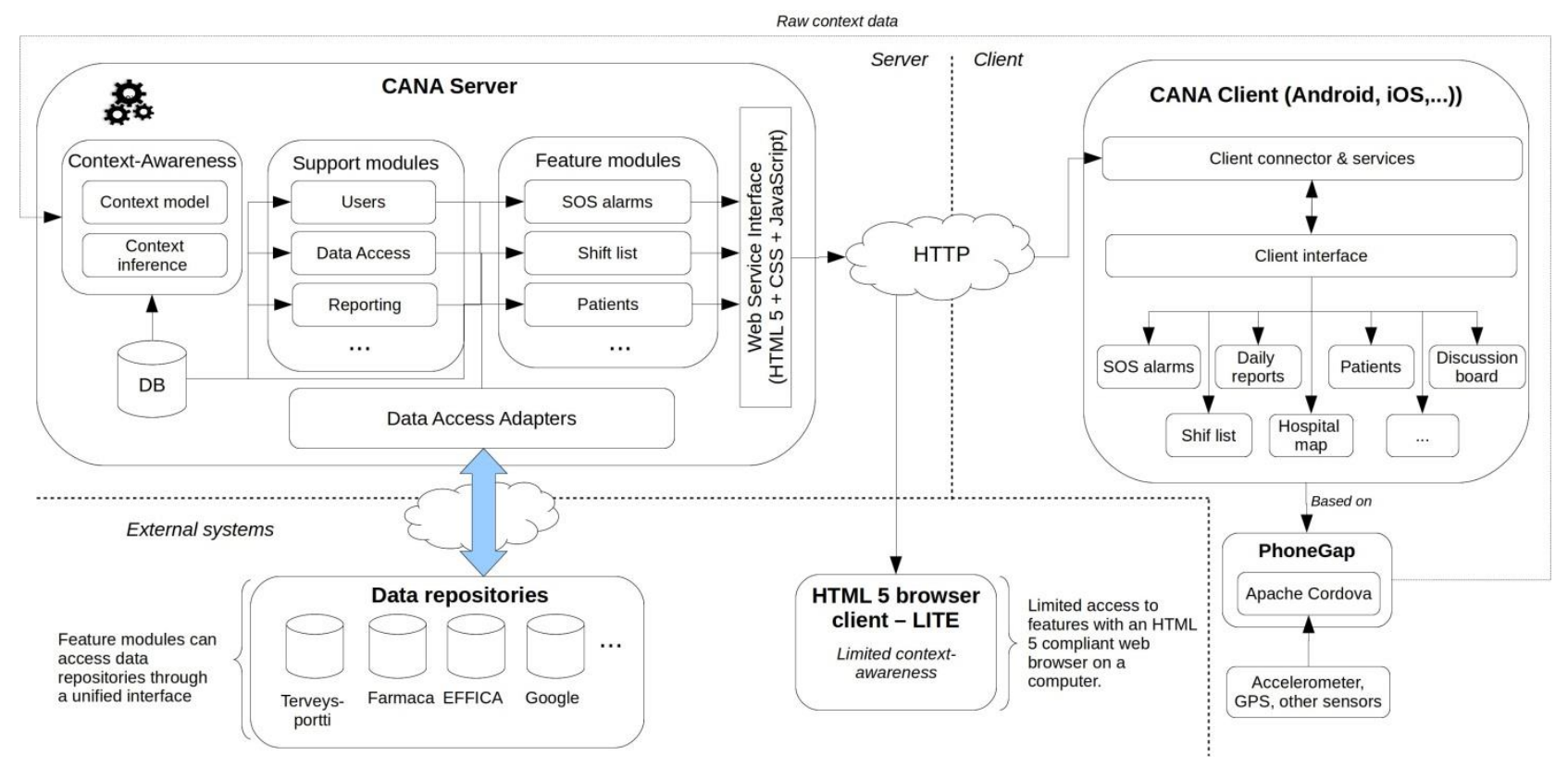

Figure 6. CANA architecture

The server's Data Access Adapters manage connections to various open and closed data repositories through the Adapter software design pattern. Data repositories could be, for example, public transport APIs (e.g., HSL in Finland), medical databases, online professional communities, and so on. Feature modules can access these repositories through the Data Access Adapters' unified interface, thus simplifying feature development. Furthermore, using the adapter interface, the server can be extended later with adapters that connect to new repositories.

The client connects to the server's Web Service Interface which provides a façade to access other server modules. The Web Service Interface is based on a HTML5, CSS and JavaScript. The server should be able to acquire raw sensor data from the client in order to use it in the context-awareness module. This data, captured by smartphone sensors (e.g., accelerometer, GPS) cannot be directly accessed by aforementioned technologies. Thus, the CANA client is based on the Phonegap framework [38] which utilizes the Apache Cordova [39] platform that enables cross-platform mobile application development using HTML5, CSS and JavaScript. Developers using Apache Cordova can essentially build mobile applications without native code. The platform also provides a JavaScript API to smartphone's hardware, including but not limited to accelerometer, GPS, camera and compass. This way, the client can supply inputs necessary for implementing the context-aware features of CANA.

\section{PROTOTYPE EVALUATION}

A low-fidelity prototype of CANA was developed using the HTML5 and CSS3 technologies. The prototype was not fully functional and it only contained main categories and sub categories for the services. Its user interface was designed to be responsive with consideration of desktop, tablet and smartphone browsers. The evaluations were carried out with smartphones in order to mimic a real world environment.
The prototype was evaluated with five users age between 21 to 60 years old (4 females, 1 male) who also participated in the initial user study. The evaluations were conducted in one-to-one sessions with four users at Aurorankoti elderly house and one user at Kuusikoti elderly house as follows. First the participants were given a set of tasks to complete one by one. They were asked to think aloud when they were carrying out the tasks. The evaluation sessions were recorded for analysis. Additionally, a semi-structured interview was conducted after each session in order to learn more about the participants' experiences with the prototype.

We defined the evaluation tasks so that they required the participants to navigate through the prototype screens. For example, we asked the participants to: 1 . Login to the system; 2. after login, find the patient (given name "Timo"); 3. Find what medical tests "Timo" needs today. Other tasks followed similar stepwise pattern.

The objective of this evaluation was to measure the prototype's overall design and concept's feasibility. The analysis of data indicates that $100 \%$ of the test users considered the application as unique and excellent. Statement such as "I never ever thought that I can perform my work related tasks with my mobile" was repeatedly heard from the participants. The surprising fact for the researchers was that even the expert participants, i.e. those who were familiar with smart devices, were surprised to see such an application. This indicates that the user data analysis and concept development using the UCD framework were successful.

By analyzing the evaluation results we have assessed: How easyto-use the user finds the required functions? Does the user find a function in the right place? Where do users often expect to see a function? How fast do users find the required functions? Is there a big navigational difference between novice and expert users?

Here are the summary of what we have found based on the mentioned assessment questions. The test analysis indicates that the application navigation was easy for both novice and expert users. 
There were, however, some labels such as "Shift list" in General services category that confused almost all participants with term timetable. Base on the evaluation, we replaced and renamed some services. As a result the navigation in some parts due to the terminology was not as smooth as we anticipated. However we have not received complains about the functions or services that needed in elderly houses. The prototype contained all the necessary function that nurses need in their work related tasks. We gained valuable experience by conducting the test, after we analyzed the prototype evaluation data we slightly modify the categories in order to make some service more visible for faster accessibility.

We did not collect feedback about the performance and the functionality as the application was a low-fidelity prototype. However, we acquired some useful suggestions regarding functionality, such as adding SOS alert to all screens and highlight them to draw the nurses' attention. Furthermore, the inclusion of a timecard feature in the system emerged during the evaluation. A timecard feature would allow automatic registration of an employee's entrance to and exit from the work premises - these tasks are currently performed manually.

The aim of semi-structured interviews was to further assess the user experience of the CANA system among nurses. We asked the participants what they think about having this application to assist in their daily work. The analysis shows that the participants enjoyed using the prototype - we did not receive even a single negative comment from them. This positive experience motivates us to pursue the implementation CANA in order to deploy it for field evaluations.

\section{DISCUSSION}

Based on the results of this paper, it is evident that a mHealth application is needed to consolidate work activities of nurses at two elderly houses in Espoo, Finland. Our initial user study revealed a lack of proper mobile application that would assist nurses in their work related tasks. The initial study also indicated that nurses are mainly using pre-installed mobile applications, such as a calendar or a browser, to facilitate their work activities. In addition to having usability challenges, the pre-installed applications often lack functionalities to support work related tasks. For example, calendar data cannot be shared with groups or be connected to existing hospital information systems. Pre-installed applications also have security related concerns which make them difficult to utilize as a healthcare application suite.

Results of the initial user study further suggested that nurses are positive towards a smartphone application that would consolidate their work activities. Based on the study, we identified services that nurses expect to have in a mHealth application (Error! Reference source not found.). These services formed the basis for the proposed Context-Aware Nurse Assistant (CANA) concept which is able to change its behavior based on the user's context, and can therefore provide appropriate services to nurses at the right time and right place. Through context-awareness, CANA provides only those features that are necessary to assist a nurse's work in a given situation, thus supporting their work more efficiently.

The evaluation results of CANA prototype indicate that nurses were excited about the CANA concept and usefulness of its features to their work activities. This is significant because research has shown that an important factor for technology acceptance among nurses is perceived usefulness [40], [41]. This result is further strengthened by an author's personal experience and our analysis of the semi-structured interview conducted after the evaluation. Technology acceptance and excitement thereof stem from performing the tasks with a familiar tool (i.e. the user's smartphone).

The CANA concept was created using a design framework based on UCD. Nurses participating in the study had crucial roles in all stages from requirement elicitation to concept creation to prototype evaluation. As the evaluation results suggest, the CANA concept was appealing to nurses. From our perspective, UCD performed satisfactorily as a design method for a context-aware healthcare application. We will continue to apply UCD through an iterative design-implementation-evaluation cycle in order to transform the CANA concept into a deployable product based on the nurses' feedback.

Compared with other sectors, such as business and education, smartphones are not yet widely utilized in healthcare to support nurses' work related tasks. There are many understandable reasons, such as security or privacy, for not having a dedicated application for nurses running on their smartphones. The security and privacy concerns form an important challenge to resolve in the product development phase.

At the moment of writing this paper, a group of municipalities in southern Finland, including Helsinki, is replacing their existing healthcare systems with a common system under the Apotti Programme ${ }^{1}$. The goal Apotti is to integrate various incompatible tools and services into a single system to facilitate eHealth services. The current design of the architecture does not mention mobile or context-aware services. Hence, the proposed CANA concept could complement the Apotti system's lack of user mobility. Conversely, CANA would benefit from Apotti's integrated tools and unified interfaces to data sources, which are essential for nurses who work in several locations throughout a week.

\section{CONCLUSION}

We proposed a novel Context-Aware Nurse Assistant (CANA) application that consolidates daily work activities of nurses through context-aware service provision. Using a design framework based on User Centered Design, we invited target users (i.e. nurses) to partake in the design process of CANA. By co-designing with a group of nurses from the beginning, we ensured that the CANA system meets the professional requirements of the nurses' work. After eliciting the essential requirements with nurses, we developed a concept and a low-fidelity prototype to evaluate the concept's feasibility. Positive evaluation results on the prototype suggest that the concept is ready for functional implementation and evaluation.

We have taken the first steps towards creating a context-aware tool that could enhance nurses' daily work activities. However, there remain several research challenges to be tackled before the CANA system can be deployed. Firstly, handling patients' data involves security and privacy challenges that must be met with appropriate techniques and policies. Secondly, CANA should be able to communicate with various proprietary, subscription-based systems such as medical databases and patient information systems. Thus, administrative and technical challenges related to gaining access to external systems must be solved in order to implement all requested features. Thirdly, we must proceed with a functional prototype implementation and evaluation in order to refine the features and the architecture. In the process, we will continue applying the UCD framework used in this study.

${ }^{1}$ http://www.hel.fi/hki/apotti/fi/Apotti-hanke/English 


\section{ACKNOWLEDGMENTS}

This study was done with support of Aurorankoti department no 5 and Kuusikoti elderly house in Espoo, Finland. Special thanks to supervisors, nurses and doctors in these two institutions.

\section{REFERENCES}

[1] J. Gebauer and M. J. Shaw, "Success Factors and Impacts of Mobile Business Applications: Results from a Mobile eProcurement Study," Int. J. Electron. Commer., vol. 8, no. 3, pp. $19-41,2004$.

[2] A. Holzinger, P. Treitler, and W. Slany, "Making Apps Useable on Multiple Different Mobile Platforms: On Interoperability for Business Application Development on Smartphones," in Proceedings of the CD-ARES 2012, 2012, pp. 176-189.

[3] P. Thornton and C. Houser, "Using mobile phones in education," in Proceedings of Wireless and Mobile Technologies in Education, 2004, pp. 3-10.

[4] J. C. Phillippi and T. H. Wyatt, "Smartphones in Nursing Education," Comput. Informatics, Nurs., vol. 29, no. 8, pp. 449454, 2011

[5] Y.-C. Hsu, H.-N. Ho, C.-C. Tsai, G.-J. Hwang, H.-C. Chu, C.-Y. Wang, and N.-S. Chen, "Research trends in technology-based learning from 2000 to 2009: A content analysis of publications in selected journals," Educ. Technol. Soc., vol. 15, no. 2, pp. 354-370, 2012.

[6] M. Robb and T. Shellenbarger, "Using technology to promote mobile learning: engaging students with cell phones in the classroom.," Nurse Educ., vol. 37, no. 6, pp. 258-261, 2012.

[7] R. F. Kenny, C. Park, J. M. C. van Neste-Kenny, P. A. Burton, and J. Meiers, "Using Mobile Learning to Enhance the Quality of Nursing Practice Education," in Mobile Learning:

Transforming the Delivery of Education and Training, M. Ally, Ed. AU Press, Athabasca University, 2010, pp. 75-98.

[8] G. Eysenbach, "CONSORT-EHEALTH: improving and standardizing evaluation reports of web-based and mobile health interventions.," J. Med. Internet Res., vol. 13, no. 4, 2011.

[9] Y. Hao and R. Foster, "Wireless body sensor networks for health-monitoring applications," Physiol. Meas., vol. 29, no. 11, p. R27, 2008.

[10] K.-H. Park and J.-G. Pak, "An integrated gateway for various PHDs in U-Healthcare environments," J. Biomed. Biotechnol., vol. 2012, 2012

[11] T. H. Laine, C. W. Lee, and H. J. Suk, "Mobile gateway for heterogeneous sensors using ZigBee and Bluetooth," in Proceedings of the 8th International Conference on Innovative Mobile and Internet Services in Ubiquitous Computing, 2014.

[12] P. Hämäläinen, J. Reponen, I. Winblad, J. Kärki, M. Laaksonen, H. Hyppönen, and M. Kangas, "eHealth and eWelfare in Finland," 2013.

[13] City of Espoo, "Täyttä elämää ikääntyneenä: Espoon ikääntymispoliittinen ohjelma 2009-2015, Sosiaali- ja terveystoimen julkaisusarja 2/2009," 2009.

[14] Citizins' online service 2013. . (www.kanta.fi) [accessed 21.04.2014]

[15] M. Suckcharoen and J. Hellberg, "Lapsiperheiden eterveyspalveluiden kartoitus," Laurea University of Applied Sciences, 2012.

[16] K. Rautio and K. Uutela, "Espoon kaupungin Terveyskansiopalvelu käyttäjänoppaan uudistaminen," Laurea University of Applied Sciences, 2013.

[17] E. Rezende, M. Melo, E. Tavares, A. Santos, and C. de Souza, "Ethics and eHealth: reflections for a safe practice," Rev. Panam. Salud Publica, vol. 28, pp. 58-65, 2010.

[18] D. A. Norman and S. W. Draper, User Centered System Design; New Perspectives on Human-Computer Interaction. Hillsdale, NJ: L. Erlbaum Associates Inc., 1986.

[19] World Health Organization, "mHealth: New horizons for health through mobile technologies," Glob. Obs. eHealth Ser., vol. 3, 2011.
[20] H. Larkin, "mHealth.," Hosp. Health Netw., vol. 85, pp. 22-6, 2 , 2011.

[21] S. Havelka, "Mobile Resources for Nursing Students and Nursing Faculty," J. Electron. Resour. Med. Libr., vol. 8, no. 2, pp. 194-199, 2011.

[22] T. Wyatt and P. Krauskopf, "E-health and Nursing: Using Smartphones to Enhance Nursing Practice.," Online J. Nurs. Informatics, vol. 16, no. 2, pp. 10-14, 2012.

[23] P. J. Brown, J. D. Bovey, and X. Chen, "Context-aware applications: From the laboratory to the marketplace," IEEE Pers. Commun., vol. 4, no. 5, pp. 58-64, 1997.

[24] A. Dey, "Context-aware computing: The CyberDesk project," in Proceedings of the AAAI 1998 Spring Symposium on Intelligent Environments, 1998, pp. 51-54.

[25] G. Chen and D. Kotz, "A Survey of Context-Aware Mobile Computing Research," 2000

[26] S. P. Nelwan, T. B. van Dam, P. Klootwijk, and S. H. Meij, "Ubiquitous mobile access to real-time patient monitoring data," Comput. Cardiol., vol. 29, pp. 557-560, 2002.

[27] J. E. Bardram, "Applications of context-aware computing in hospital work: examples and design principles," in $A C M$ symposium on Applied computing, 2004, pp. 1574-1579.

[28] J. E. Bardram, T. R. Hansen, M. Mogensen, and M. Soegaard, "Experiences from Real-World Deployment of Context-Aware Technologies in a Hospital Environment," in International Conference on Ubiquitous Computing, 2006, pp. 369-386.

[29] J. D. Gould and C. Lewis, "Designing for usability: key principles and what designers think," Commun. ACM, vol. 28, no. 3, pp. 300-311, 1985.

[30] J. D. Gould, S. J. Boies, and J. Ukelson, "How to Design Usable Systems," in Handbook of Human Computer Interaction, M. G. Helander, T. K. Landauer, and P. V. Prabhu, Eds. Elsevier Science, 1997, pp. 231-254.

[31] A. Dirin and M. Nieminen, "Framework for addressing usability and user experience in m-learning," J. Comput., vol. in press, 2014.

[32] ISO, "Ergonomics of human-system interaction - Part 210: Human-centred design for interactive systems (ISO 9241210:2010)." 2010.

[33] J. Saldana, "An Introduction to Codes and Coding," in The coding manual for qualitative researchers, Los Angeles: Sage Publications, 2009, pp. 1-31.

[34] K. Holtzblatt, J. B. Wendell, and S. Wood, "Chapter 8 Building an Affinity Diagram," in Interactive Technologies, 2005, pp. 159-179.

[35] J. T. Hackos and J. C. Redish, User and Task Analysis for Interface Design, vol. 42. John Wiley \& Sons, 1998.

[36] M. B. Rosson and J. M. Carroll, "Scenario-Based Design," in The human-computer interaction handbook: fundamentals, evolving technologies and emerging applications, 2002, pp. 1032-1050.

[37] Hui Liu, H. Darabi, P. Banerjee, and Jing Liu, "Survey of Wireless Indoor Positioning Techniques and Systems," IEEE Trans. Syst. MAN, Cybern. Part C Appl. Rev., vol. 37, no. 6, pp. 1067-1080, 2007.

[38] Adobe Systems, "PhoneGap," 2014. [Online]. Available: http://phonegap.com/.

[39] The Apache Software Foundation, "Apache Cordova," 2014. [Online]. Available: http://cordova.apache.org/.

[40] Y. Kowitlawakul, "The technology acceptance model: predicting nurses' intention to use telemedicine technology (eICU).," Comput. Informatics, Nurs., vol. 29, no. 7, pp. 411418, 2011.

[41] S. Chow, W.-Y. Chin, H.-Y. Lee, H.-C. Leung, and F.-H. Tang, "Nurses' perceptions and attitudes towards computerisation in a private hospital.," J. Clin. Nurs., vol. 21, no. 11-12, pp. 168596, 2012. 